\title{
Conventional Imaging and Sonoelastography Findings of Oncocytic Breast Carcinoma in a Man
}

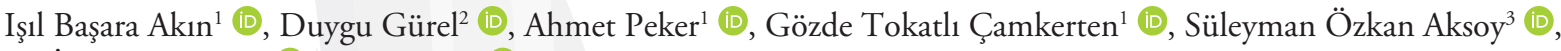 \\ Ali İbrahim Sevinç ${ }^{3}$ (D), Pınar Balcı ${ }^{1}$ (i) \\ ${ }^{1}$ Department of Radiology, Dokuz Eylül University Faculty of Medicine, İzmir, Turkey \\ ${ }^{2}$ Department of Pathology, Dokuz Eylül University Faculty of Medicine, İzmir, Turkey \\ ${ }^{3}$ Department of General Surgery, Dokuz Eylül University Faculty of Medicine, İzmir, Turkey
}

\section{ABSTRACT}

Oncocytic breast carcinoma (OBC) is one of the rare types of invasive breast carcinoma in according to the classification of The World Health Organization. Herein we represent imaging findings of a case of 69 -year-old male patient with $\mathrm{OBC}$.

Keywords: Breast imaging, mammography, oncocytic carcinoma, sonoelastography, ultrasonography

Cite this articles as: Başara Akın I, Gürel D, Peker A, Tokatlı Çamkerten G, Aksoy SÖ, Sevinç Aİ, Balıı P. Conventional Imaging and Sonoelastography Findings of Oncocytic Breast Carcinoma in a Man. Eur J Breast Health 2020; 16(4): 295-297.

\section{Introduction}

Oncocytic carcinoma is usually observed in thyroid-parathyroid glands, kidney, and pituitary glands (1). Oncocytic breast carcinoma $(\mathrm{OBC})$ is one of the rare types of invasive breast carcinoma according to the classification of The World Health Organization (WHO) and is first defined in 1987 (2). In the recent WHO blue book "oncocytic carcinoma" is considered as a different pattern in the invasive carcinoma of no special type. The main differential diagnosis of these carcinomas should be done with apocrine differentiation (3). It has also been referred as malignant oncocytoma and mammary epithelial oncocytoma (1).

In this case, we are presenting conventional breast imaging and sonoelastography findings of OBC. To our best knowledge; this is the first case representing imaging findings of $\mathrm{OBC}$ in a man.

\section{Case Presentation}

A 69-year old male patient admitted to general surgery outpatient clinic with chief complaint of a palpable lesion increasing in size at his right subareolar region for 5 years. Except a deep vein thrombosis in his medical history, neither he has a comorbidity, nor he has a breast cancer history in his family. In physical examination, a mobile, tough mass was detected at his right subareolar region. He was redirected to our breast imaging section for further evaluations. Mammography (MG) and ultrasonography (US) examinations were performed. In MG, a round shaped, hyperdense nodular microlobulated lesion with focal spiculated margins was detected (Figure 1). US revealed a solid, round shaped, macrolobulated solid mass with heterogeneous echogenicity. It was located in vertical orientation. In coloured Doppler US, the lesion had an increased internal vascularity (Figure 2). Strain elastography examination showed that the lesion was depicted predominantly red colour that was compatible with increased strain. In shear wave elastography the stiffness value was measured as $7.64 \mathrm{~m} / \mathrm{sec}$ and $231.02 \mathrm{Kpa}$ (Figure 3). Lesion was classified as BI-RADS 4B and was excised on demand of the patient. In macroscopic evaluation, the dimensions of the tumour were $3 \times 1.5 \mathrm{~cm}$. Additionally, the tumour had lobulated contour and grey-white colour. Under microscope, the histopathologic degree (Nottingham) of the tumour was 2 . The score of the tubule formation was 3, nuclear pleomorphism score was 2 and mitosis was 1 . The surgical margin was negative, the tumour included necrosis and there were a few lymphocytic infiltrations. There was no elastosis, peritumoral lymphovascular invasion, peripheral nerve, skin, areola and fascia invasions. The pathologic stage was pT2N0 (sentinel node). The immunohistochemical markers showed that oestrogen $(100 \%,+++)$ and progesterone $(80 \%,+++)$ receptors were positive. C-erb-B-2 was negative whereas ki67 proliferation index was approximately 10\%. Additional immunohistochemical markers including androgen $(90 \%,+++)$, mito (diffuse +), CK7, GCDFP15, GATA 3 and EMA were positive. The final pathology report was $\mathrm{OBC}$ for the lesion (Figure 4). 


\section{Discussion and Conclusion}

The OBC is an extremely rare form of breast carcinoma and usually occurs at older ages and in men also (1). In OBC, oncocytic cells are detected more than $60 \%$. The word oncocytic means 'swollen cells'. Mitochondria accumulations are seen in these swollen cells. The OBCs at other sites of the body are benign tumours, however, in breasts, they are malignant tumours. The OBC are commonly solid tumours without glandular differentiation. Besides, there is focal ductal differentiation formed by large aggregates of neoplastic cells (4).

Of $0.7 \%$ breast cancers are diagnosed in men (5). The most common histopathologic subtype is invasive ductal carcinoma with

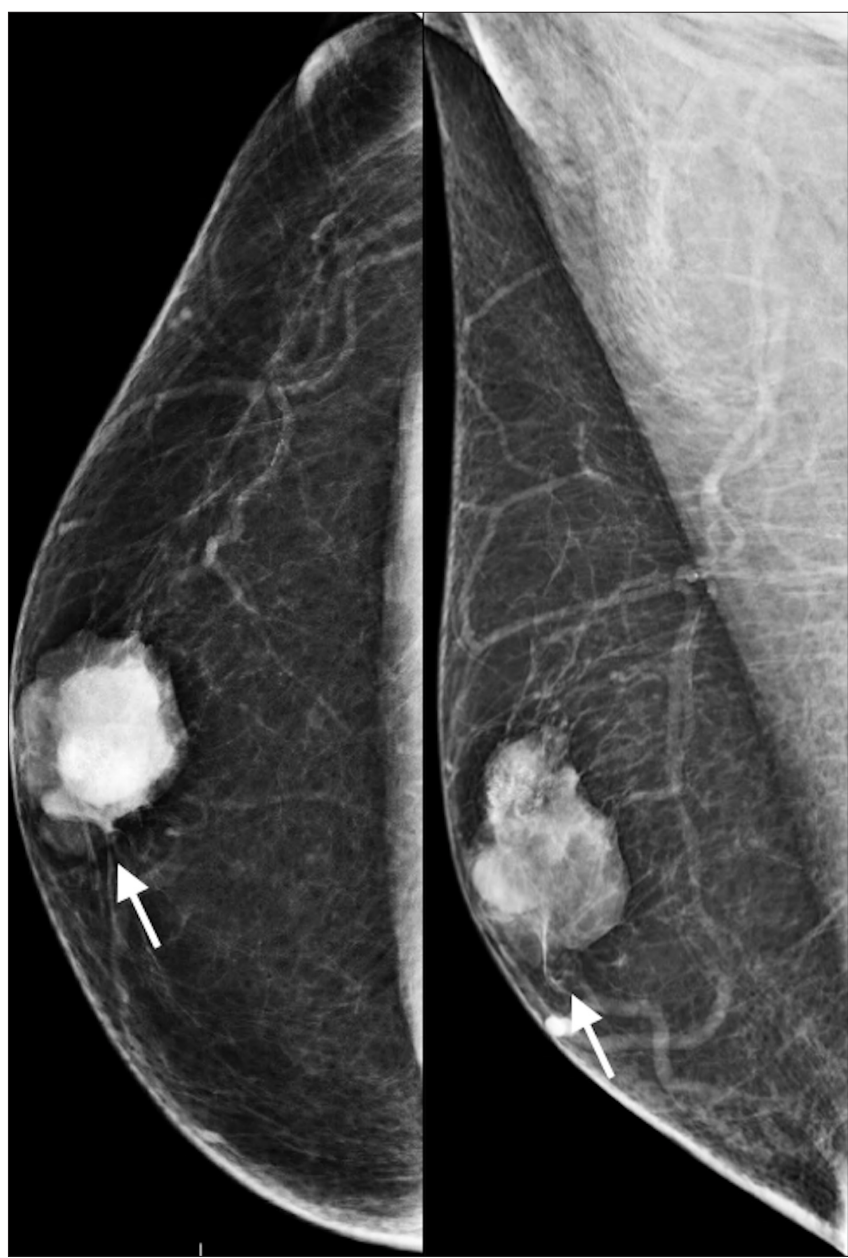

Figure 1. Mammography image showing a round shaped, hyperdense nodular lesion. There are microlobulated and focal spiculated margins (Arrow)

\section{Key Points}

- The breast lesion are mostly challenging in male patients. Recognition of breast lesions of male patients provide applying optimal treatment options.

- Oncocytic breast carcinoma is one of the rare types of invasive breast carcinoma and these tumors can be also seen in male patients.

- As oncocytic breast carcinoma a type of malignant tumor, sonoelastography findings have high stiffness values dependent on the histopathologic features of this tumor.
$80 \%$ and the second subtype is ductal carcinoma in situ with $5 \%$ (6). Mixed types, invasive papillary carcinoma, both breast carcinoma, and extramammary primary malignancy metastases are other malignant male breast lesions. Invasive lobular carcinoma is a rare subtype of male breast cancer (6). Male malign breast lesions have similar imaging findings with women. They usually locate at subareolar region. They are commonly represented a painless palpable lesion (6). Lesions are palpated as round, oval or irregular masses. Calcifications can be seen in radiology examinations
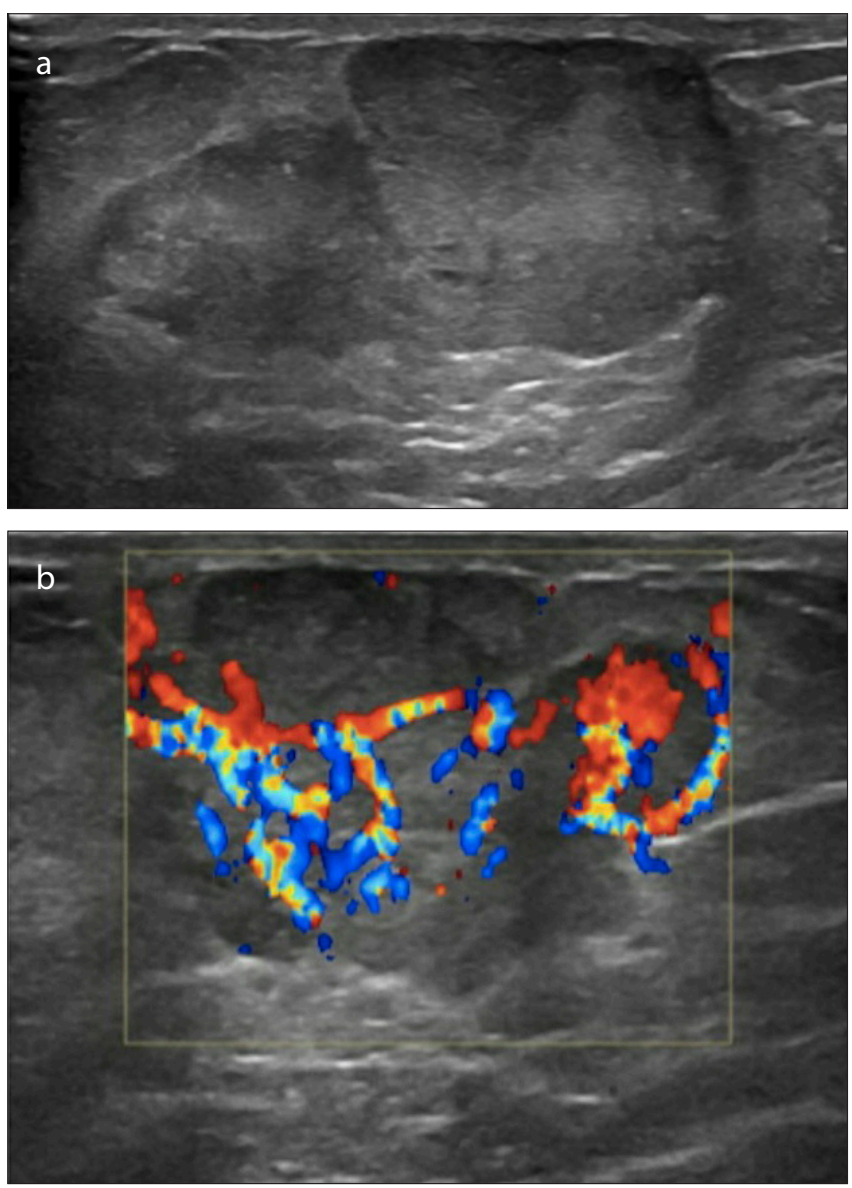

Figure 2. a, b. (a) Ultrasonography, (b) Doppler Ultrasonography. The lesion is round shaped, macrolobulated solid mass with heterogeneous echogenicity. The lesion had an increased internal vascularity

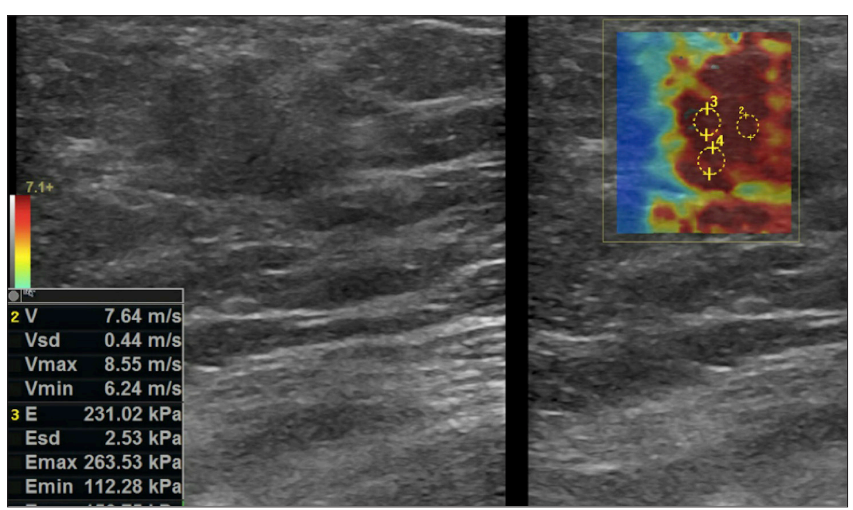

Figure 3. Shear wave elastography image reveals predominantly red colour, which was compatible with increased strain. The stiffness value was measured as $7.64 \mathrm{~m} / \mathrm{sec}$ and $231.02 \mathrm{Kpa}$ 

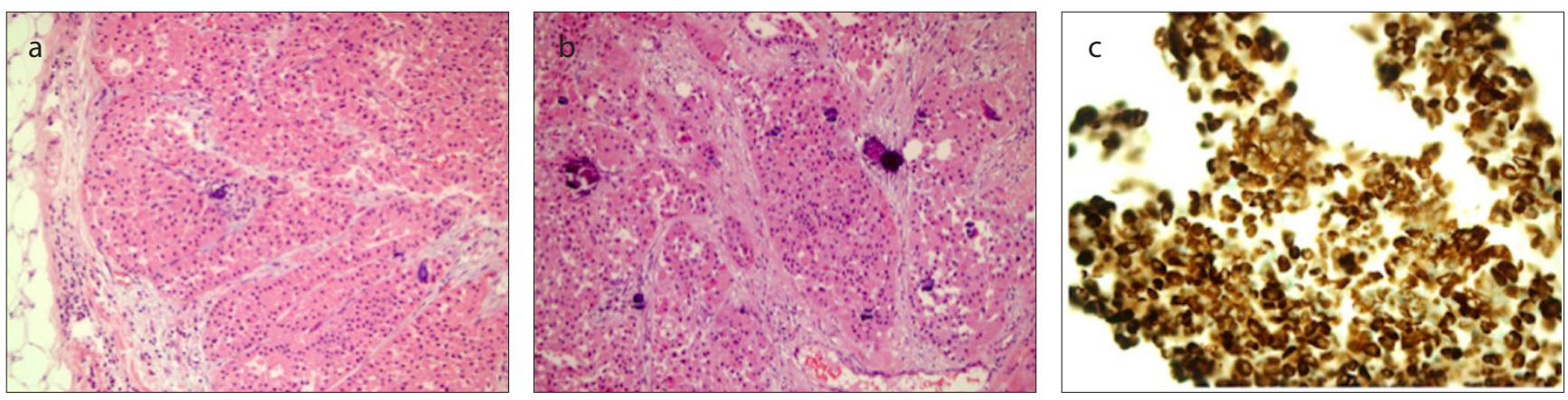

Figure 4. a-c. (a) $H \& E, x 10$, (b) $H \& E, x 20$, (c) Immunostaining (x40). H\&E, x10 image shows well-circumscribed nodular appearance of the tumour. There are cells with abundant eosinophilic granular cytoplasm in $\mathrm{H} \& \mathrm{E}, \mathrm{x} 20$. The immunostaining with an antibody to mitochondria highlights coarse cytoplasmic granules

however, these are rare in men than women and commonly course calcifications occur (7).

In our case, conventional imaging findings including MG and US revealed that the lesion had no obvious imaging finding in order to differentiate this tumour from other malignant breast lesions. Sonoelastography findings pointed high stiffness values in the tumour. We think that this elastography findings with high stiffness values were dependent on the histopathologic structure of the tumour. As mentioned above, the tumour is formed by mitochondria accumulated swollen cells. Additionally, they are solid tumours without glandular differentiations (4).

The published literature can count on the one hand the $\mathrm{OBC}$ cases (8). Furthermore, clinical features of $\mathrm{OBC}$ are similar to invasive ductal carcinoma and the treatment options are identical (8). As it is a rare type of breast carcinoma, there is no evident knowledge of the effect of radiotherapy to this tumor $(9,10)$.

Finally, OBCs are very rare form of breast carcinoma and there are a few numbers of cases in the literature. Conventional imaging findings do not have specific distinctive features from usual breast cancer types in men. Sonoelastography findings have high stiffness values dependent on the histopathologic features of this tumor. Our case is the first case representing both conventional imaging and sonoelastography findings of $\mathrm{OBC}$, in the literature. As there are uncertain data about this type of tumor, this diagnosis should be kept in mind and suspicious lesions should be histopathologically evaluated.

Informed Consent: Written informed consent was obtained from the patient who participated in this study.

Peer-review: Externally peer-reviewed.

Author Contributions: Concept - I.B.A.; Design - I.B.A., A.P.; Supervision A.İ.S., P.B.; Resources - D.G., S.Ö.A.; Materials - I.B.A., G.T.Ç.; Data Collection and/or Processing - A.P., G.T.Ç.; Analysis and/or Interpretation - I.B.A., S.Ö.A., D.G.; Literature Search - A.P., G.T.Ç.; Writing Manuscript - I.B.A.; Critical Review - A.İ.S., P.B.; Other - I.B.A., A.P., G.T.Ç.
Conflict of Interest: The authors have no conflicts of interest to declare.

Financial Disclosure: The authors declared that this study has received no financial support.

\section{References}

1. Máximo V, Rios E, Sobrinho-Simôes M. Oncocytic lesions of the thyroid, kidney, salivary glands, adrenal cortex, and parathyroid glands. Int J Surg Pathol 2014; 22: 33-36. (PMID: 24406625) [Crossref]

2. Sinn HP, Kreipe H. A Brief Overview of the WHO Classification of Breast Tumors, 4th Edition, Focusing on Issues and Updates from the 3rd Edition. Breast Care (Basel) 2013; 8: 149-154. (PMID: 24415964) [Crossref]

3. Hoon Tan P, Ellis I, Allison K, Brogi E, Fox SB, Lakhani S, Lazar AJ, Morris EA, Sahin A, Salgado R, Sapino A, Sasano H, Schnitt S, Sotiriou C, van Diest P, White VA, Lokuhetty D, Cree IA; WHO Classification of Tumours Editorial Board. The 2019 WHO Classification of Tumours of The Breast. Histopathology 2020; DOI: 10.1111/his.14091. (PMID: 32056259) [Crossref]

4. Coyne JD, Dervan PA. Primary acinic cell carcinoma of the breast. J Clin Pathol 2002; 55: 545-547. (PMID: 12101208) [Crossref]

5. Giordano $\mathrm{SH}$. A review of the diagnosis and management of male breast cancer. Oncologist 2005; 10: 471-479. (PMID: 16079314) [Crossref]

6. Mathew J, Perkins GH, Stephens T, Middleton LP, Yang WT. Primary breast cancer in men: clinical, imaging, and pathologic findings in $57 \mathrm{pa}-$ tients. AJR Am J Roentgenol 2008; 191: 1631-1639. (PMID: 19020230) [Crossref]

7. Nguyen C, Kettler MD, Swirsky ME, Miller VI, Scott C, Krause R, Handro JA. Male breast disease: pictorial review with radiologic-pathologic correlation. Radiographics 2013; 33: 763-779. (PMID: 23674773) [Crossref]

8. Ragazzi M, de Biase D, Betts CM, Fernadi A, Sezgin Ramadan S, Tallini G, Reis-Filho JS, Eusebi V. Oncocytic carcinoma of the breast: frequency, morphology and follow-up. Hum Pathol 2011; 42: 166-175. (PMID: 21111455) [Crossref]

9. Marucci G, Betts CM, Frank G, Foschini MP. Oncocytic meningioma: report of a case with progression after radiosurgery. Int J Surg Pathol 2007; 15: 77-81. (PMID: 17172505) [Crossref]

10. Ambrosini-Spaltro A, Salvi F, Betts CM, Frezza GP, Piemontese A, Del Prete P, Baldoni C, Foschini MP, Viale G. Oncocytic modifications in rectal adenocarcinomas after radio and chemotherapy. Virchows Arch 2006; 448: 442-448. (PMID: 17172505) [Crossref] 